\title{
Subcortical Control of Precision Grip after Human Spinal Cord Injury
}

\author{
Karen L. Bunday, ${ }^{1}$ Toshiki Tazoe, ${ }^{1}$ John C. Rothwell, ${ }^{2}$ and Monica A. Perez ${ }^{1}$ \\ ${ }^{1}$ University of Pittsburgh, Department of Physical Medicine and Rehabilitation, Center for the Neural Basis of Cognition, Systems Neuroscience Institute, \\ Pittsburgh, Pennsylvania 15261, and 2Institute of Neurology, University College London, London, WC1N 3BG, United Kingdom
}

\begin{abstract}
The motor cortex and the corticospinal system contribute to the control of a precision grip between the thumb and index finger. The involvement of subcortical pathways during human precision grip remains unclear. Using noninvasive cortical and cervicomedullary stimulation, we examined motor evoked potentials (MEPs) and the activity in intracortical and subcortical pathways targeting an intrinsic hand muscle when grasping a small $(6 \mathrm{~mm})$ cylinder between the thumb and index finger and during index finger abduction in uninjured humans and in patients with subcortical damage due to incomplete cervical spinal cord injury (SCI). We demonstrate that cortical and cervicomedullary MEP size was reduced during precision grip compared with index finger abduction in uninjured humans, but was unchanged in SCI patients. Regardless of whether cortical and cervicomedullary stimulation was used, suppression of the MEP was only evident $1-3 \mathrm{~ms}$ after its onset. Long-term ( $\sim 5$ years $)$ use of the GABAb receptor agonist baclofen by SCI patients reduced MEP size during precision grip to similar levels as uninjured humans. Index finger sensory function correlated with MEP size during precision grip in SCI patients. Intracortical inhibition decreased during precision grip and spinal motoneuron excitability remained unchanged in all groups. Our results demonstrate that the control of precision grip in humans involves premotoneuronal subcortical mechanisms, likely disynaptic or polysynaptic spinal pathways that are lacking after SCI and restored by long-term use of baclofen. We propose that spinal GABAb-ergic interneuronal circuits, which are sensitive to baclofen, are part of the subcortical premotoneuronal network shaping corticospinal output during human precision grip.
\end{abstract}

Key words: Baclofen; corticospinal drive; primary motor cortex; spasticity; spinal motoneurons; voluntary drive

\section{Introduction}

The neural control of precision grip in mammals has been associated with the contribution of the motor cortex and the corticospinal system (Lemon, 2008). Electrophysiological studies in primates showed that monosynaptic corticomotoneuronal cells are significantly active during a precision grip task requiring fractionated digit movements (Buys et al., 1986; Maier et al., 1993; Bennett and Lemon, 1996). Furthermore, lesions of the motor cortex (Hoogewoud et al., 2013) or the corticospinal tract at the brainstem level impaired dexterous finger movements (Lawrence and Kuypers, 1968; Galea and Darian-Smith, 1997; Zaaimi et al., 2012). Consistently, studies in human showed that damage to the motor cortex or the corticospinal tract reduced the ability to perform independent finger movements (Lang and Schieber, 2003, 2004).

\footnotetext{
Received Jan. 28, 2014; revised March 13, 2014; accepted April 16, 2014.

Author contributions: K.L.B., T.T., J.C.R., and M.A.P. designed research; K.L.B., T.T., J.C.R., and M.A.P. performed research; K.L.B., T.T., J.C.R., and M.A.P. contributed unpublished reagents/analytic tools; K.L.B., T.T., J.C.R., and M.A.P. analyzed data; K.L.B., T.T., J.C.R., and M.A.P. wrote the paper.

This work was supported by funding from the National Institute of Neurological Disorders and Stroke-National Institutes of Health (Grant R01 NS076589) and the Department of Veterans Affairs (Grant 3397626).

The authors declare no competing financial interests.

Correspondence should be addressed to Monica A. Perez, PhD, Department of Physical Medicine and Rehabilitation, Center for the Neural Basis of Cognition, Systems Neuroscience Institute, University of Pittsburgh, 3501 Fifth Avenue, Pittsburgh, PA 15261. E-mail: perezmo@pitt.edu.

DOI:10.1523/JNEUROSCI.0390-14.2014

Copyright $\odot 2014$ the authors $\quad 0270-6474 / 14 / 347341-10 \$ 15.00 / 0$
}

Recent studies proposed that subcortical neuronal networks also make a significant contribution to the control of precision grip. Single unit recordings in primates showed that spinal interneurons exert postspike effects in hand muscles during a precision grip (Takei and Seki, 2010) in a task-dependent manner (Takei and Seki, 2013). Although lesions of the corticospinal tract at the cervical spinal cord level showed in most cases recovery of the ability to grasp with the index finger and thumb (Sasaki et al., 2004; Alstermark et al., 2011; Hoogewoud et al., 2013), likely related to time-dependent central compensatory mechanisms underlying the recovery of finger dexterity (Nishimura et al., 2007, 2009; Isa et al., 2013), the contribution of subcortical pathways to the control of precision grip in humans with subcortical damage due to incomplete spinal cord injury (SCI) remains unknown.

Anatomical and electrophysiological studies showed extensive reorganization in the corticospinal tract after SCI (Oudega and Perez, 2012), which may alter the ability to modulate corticospinal excitability during a motor behavior. Indeed, during voluntary contraction of finger muscles, patients with SCI show an impaired ability to recruit corticospinal drive (Davey et al., 1998) and to modulate corticospinal excitability by activity in subcortical circuits (Barry et al., 2013) compared with controls. Moreover, SCI patients are unable to modulate the gain of spinal inhibitory circuits controlled by descending inputs, including corticospinal drive, during different motor tasks (Perez and 
Table 1. SCl participants

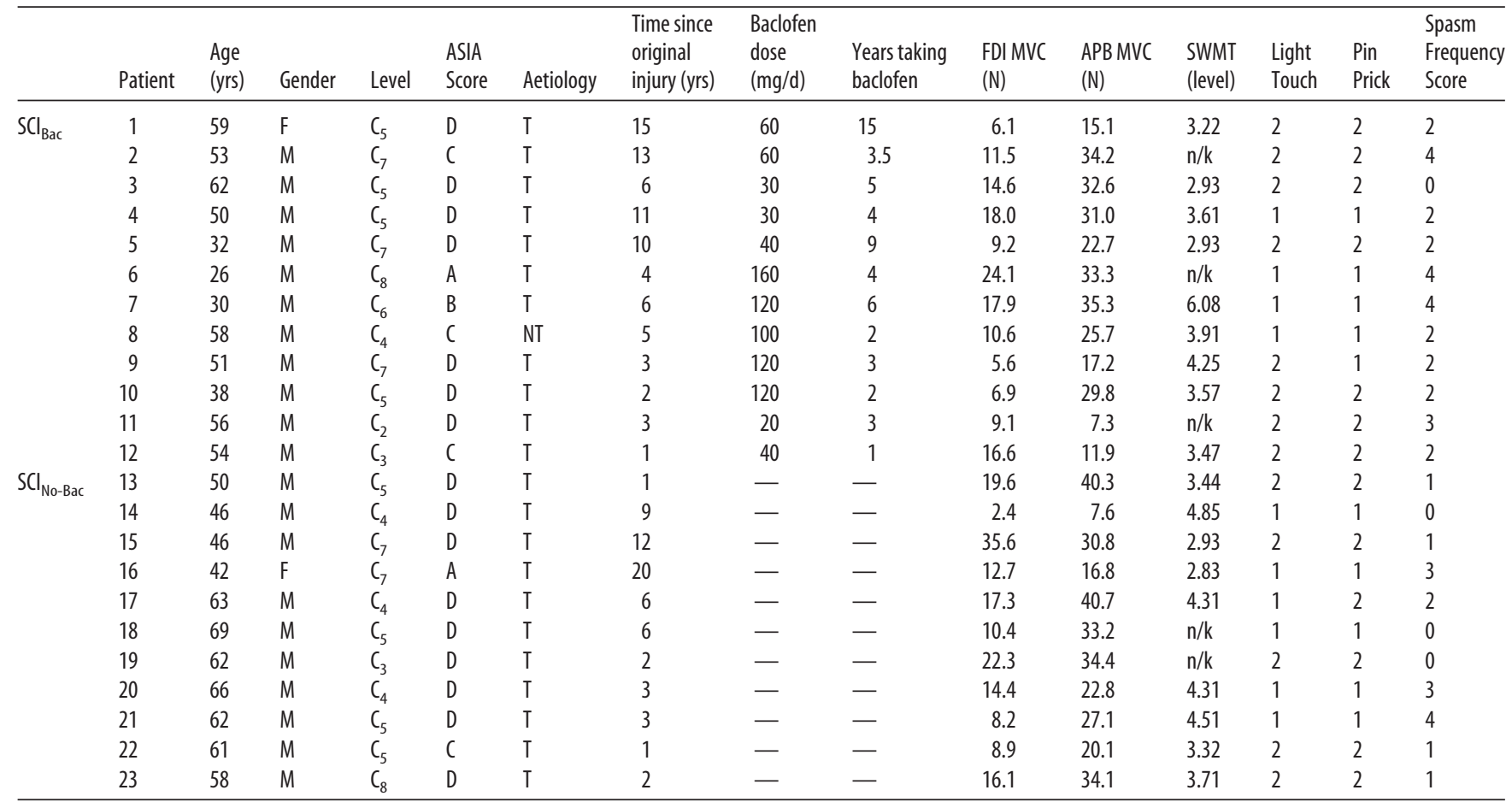

M, Male; F, Female; T, Traumatic; NT, nontraumatic.

For the SWMT: range 2.83-6.08; higher numbers = more sensory impairment; $\mathrm{n} / \mathrm{k}$, not known; for light touch and pin prick: $1=$ impaired, $2=$ intact; for spasm frequency score: $0=$ no spasms, $1=$ one or fewer spasms per day, $2=$ between 1 and 5 spasms per day, $3=5$ to $<10$ spasms per day, and $4=10$ or more spasms per day.

Field-Fote, 2003). Corticospinal excitability is modulated in a task-dependent manner during precision grip and an index finger voluntary contraction in controls at matched EMG levels (Datta et al., 1989; Flament et al., 1993; Kouchtir-Devanne et al., 2012). Although this modulation can take place at cortical and subcortical levels, we hypothesized that SCI causes abnormalities in the contribution of subcortical elements that will be restored by long-term use of the GABAb receptor agonist baclofen (Barry et al., 2013).

To test our hypothesis, we used noninvasive motor cortical and cervicomedullary stimulation to examine transmission in corticospinal, intracortical, and subcortical pathways during precision grip and an index finger abduction task at matched EMG levels. We demonstrate that premotoneuronal subcortical pathways make a significant contribution to precision grip after human SCI. We propose that spinal GABAb-ergic interneuronal circuits, which are sensitive to baclofen, may be part of the subcortical network controlling human precision grip.

\section{Materials and Methods}

Subjects. Twenty-three patients with SCI (mean age $=51.9 \pm 11.8$ years, 2 female; Table 1 ) and 20 age-matched controls (mean age $=45.2 \pm 16.2$ years, $p=0.13,8$ male) participated in the study. All subjects gave informed consent to experimental procedures, which were approved by the local ethics committee at the University of Pittsburgh. Patients had a chronic ( $\geq 1$ year), cervical injury $(\mathrm{C} 2-\mathrm{C} 8$ ), an intact (score $=2$ ) or impaired (score $=1$ ), but not absent, innervation in dermatome C6 during light touch and pin prick stimulus using the American Spinal Cord Injury Association (ASIA) sensory scores, and residual hand motor function. The Semmens-Weinstein monofilament test (SWMT) was used to assess cutaneous sensibility in dermatome C6 in all patients (Kalsi-Ryan et al., 2012). Two of 23 patients were categorized as ASIA-A (complete injury) due to the lack of sacral sparing (Marino et al., 2003) despite being able to elicit voluntary force with hand muscles, one patient was classified as ASIA-B, and the other 20 patients were classified as incomplete ASIA-C and ASIA-D. Twelve SCI patients took baclofen $\left(\mathrm{SCI}_{\mathrm{Bac}}\right)$ as part of their daily drug therapy for $4.8 \pm 3.8$ years (Table 1$)$ and 11 SCI patients had never taken baclofen since their diagnosis $\left(\mathrm{SCI}_{\mathrm{No}-\mathrm{Bac}}\right)$. Participants were able to exert maximal voluntary contraction (MVC) isometric forces into index finger abduction [controls $=$ $17.8 \pm 5.5$ Newtons $(\mathrm{N}), \mathrm{SCI}_{\mathrm{Bac}}=12.6 \pm 5.6 \mathrm{~N}, \mathrm{SCI}_{\mathrm{No}-\mathrm{Bac}}=15.1 \pm 8.9$ $\left.\mathrm{N} ; F_{(2,42)}=2.4 ; p=0.10\right]$ and thumb abduction (controls $=34.9 \pm 8.1$ $\mathrm{N}, \mathrm{SCI}_{\mathrm{Bac}}=24.5 \pm 9.5 \mathrm{~N}, \mathrm{SCI}_{\mathrm{No}-\mathrm{Bac}}=28.2 \pm 10.3 \mathrm{~N} ; F_{(2,39)}=4.5 ; p=$ $0.02)$.

Recordings. EMG was recorded from the first dorsal interosseous (FDI) and abductor pollicis brevis (APB) of the right side in controls and from the less affected hand in patients with SCI through surface electrodes secured to the skin over the belly of each muscle (Ag-AgCl, $10 \mathrm{~mm}$ diameter). The signals were amplified, filtered $(20-1000 \mathrm{~Hz})$, and sampled at $2 \mathrm{kHz}$ for offline analysis (CED 1401 with Signal software, Cambridge Electronic Design). During MVCs, force exerted at the proximal interphalangeal joint of the index finger and thumb were measured by load cells (range $\pm 498.1 \mathrm{~N}$, voltage $\pm 5 \mathrm{~V}$, high-sensitivity transducer $0.045 \mathrm{~V} / \mathrm{N}$; Honeywell). Force was sampled at $200 \mathrm{~Hz}$ and stored on a computer for offline analysis.

Experimental setup. Subjects completed a precision grip and an index finger abduction task (Fig. 1) while seated in an armchair with both arms flexed at the elbow by $90^{\circ}$. During the index finger abduction task, subjects were instructed to press with the index finger against a custom lever into the abduction direction with the forearm pronated and the wrist restrained by straps (Fig. $1 B$ ). During the precision grip task, subjects were instructed to grasp a small cylinder (diameter: $6 \mathrm{~mm}$, length: 31 $\mathrm{mm}$, weight: $1.36 \mathrm{~g}$ ) between the thumb and index finger while the forearm was maintained in the neutral position and the wrist was restrained by straps (Fig. 1C). The instruction for the subjects was to maintain the cylinder in a vertical position with the minimal amount of activity in both fingers referred to as "natural precision grip." At the start of the experiment, subjects performed 3 brief MVCs ( $3-5 s)$ with the index finger and thumb that were separated by $30 \mathrm{~s}$. A familiarization trial was completed at the beginning of each experiment to ensure that subjects were able to match EMG activity in the FDI muscle during both tasks. Tasks were 


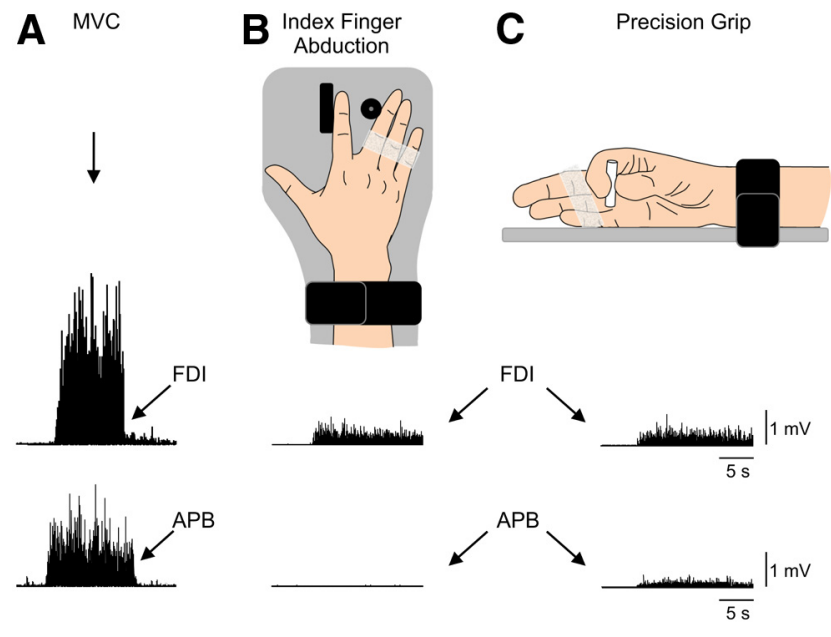

Figure 1. Experimental setup. A, Raw EMG traces showing MVC (left traces) with the index finger into abduction by activating the FDI muscle and with the thumb into abduction by activating the APB muscle. $B, C$, Schematic of the experimental setup showing the posture of the hand during index finger abduction $(\boldsymbol{B})$ and precision grip ( $\boldsymbol{C}$. Subjects were instructed by an oscilloscope to perform index finger abduction or precision grip and match EMG activity in the FDI during both motor tasks (bottom right traces). Note that control subjects completed the test with the right dominant hand and patients with $\mathrm{SCl}$ used their less affected hand.

completed in a pseudorandomized order. EMG activity from the FDI muscle was displayed continuously on an oscilloscope and verbal feedback was provided to the subjects to ensure that physiological measurements in the FDI were acquired at similar EMG activity at all times. A total of $12.6 \%$ trials in which mean rectified EMG activity exceeded \pm 1.5 $\mathrm{SD}$ of the average contracting mean rectified EMG measured $100 \mathrm{~ms}$ before the stimulus artifact were excluded from further analysis (Barry et al., 2013).

Transcranial magnetic stimulation (TMS). Transcranial magnetic stimuli were delivered from a Magstim 200 stimulator through a figure- 8 coil (loop diameter, $7 \mathrm{~cm}$; type number SP15560) with a monophasic current waveform. TMS was delivered to the optimal scalp position for activation of the left or right FDI muscle. To identify the optimal scalp position for the FDI, the coil was held tangential to the scalp with the handle pointing backward and $45^{\circ}$ away from the midline. With this coil position, the current flowed in a posterior-anterior direction and probably produced D-wave and early I-wave activation of corticospinal neurons (Sakai et al., 1997). The TMS coil was held to the head of the subject with a custom coil holder while the head was firmly secured to a headrest by straps to limit head movements. TMS measurements included motor evoked potentials (MEPs), active motor threshold (AMT), maximal MEP size (MEP-max), and suppression of voluntary EMG by subthreshold TMS (svEMG).

MEPs. AMT was defined as the minimal stimulus intensity required to induce MEPs $>200 \mu \mathrm{V}$ peak-to-peak amplitude above the background EMG in at least three of five consecutive trials in the contracting muscle (Rothwell et al., 1999; Table 2). The MEP-max was defined in all participants during index finger abduction by increasing stimulus intensities in $5 \%$ steps of maximal device output until the MEP amplitude did not show additional increases (controls $=9.4 \pm 3.0 \mathrm{mV}, n=15 ; \mathrm{SCI}_{\mathrm{Bac}}=$ $3.5 \pm 2.2 \mathrm{mV}, n=10 ; \mathrm{SCI}_{\mathrm{No}-\mathrm{Bac}}=3.3 \pm 2.1 \mathrm{mV}, n=11 ; p<0.001$ ). MEPs were tested using TMS intensities of $110 \%, 120 \%$, and $150 \%$ of the AMT (Table 2). Single TMS pulses were delivered at $4 \mathrm{~s}$ intervals in sets of 10 and separated by resting periods as needed. Twenty MEPs were averaged in each condition at each intensity and repeated two to three times. TMS pulses were given when subjects performed precision grip and index finger abduction at randomized TMS intensities. The slope of linear regression line between MEP size and TMS intensity was calculated in all subjects in each task.

Cervicomedullary MEPs. For cervicomedullary MEPs (CMEPs), the corticospinal tract was stimulated at the cervicomedullary level in controls $(n=7), \operatorname{SCI}_{\mathrm{Bac}}(n=3)$, and $\mathrm{SCI}_{\mathrm{No}-\mathrm{Bac}}(n=2)$ by a high-voltage electrical current (100 $\mu$ s duration, DS7AH; Digitimer) passed between
Table 2. Stimulation parameters and MEP size

\begin{tabular}{|c|c|c|c|c|}
\hline & Controls & $\mathrm{SCl}_{\mathrm{Bac}}$ & $\mathrm{SCl}_{\mathrm{No}-\mathrm{Bac}}$ & $p$-values \\
\hline AMT (\% MSO) & $38.3 \pm 6.9$ & $56.1 \pm 14.0$ & $59.2 \pm 14.7$ & $p<0.001$ \\
\hline \multicolumn{5}{|c|}{ Stimulation intensity (\% MSO) } \\
\hline $110 \%$ AMT & $41.9 \pm 7.8$ & $61.5 \pm 15.4$ & $64.6 \pm 16.4$ & $p<0.001$ \\
\hline $120 \%$ AMT & $46.1 \pm 7.7$ & $67.5 \pm 17.0$ & $70.3 \pm 18.0$ & $p<0.001$ \\
\hline $150 \%$ AMT & $57.7 \pm 9.0$ & $78.9 \pm 16.4$ & $82.4 \pm 17.0$ & $p<0.001$ \\
\hline \multicolumn{5}{|l|}{ MEP size (mV) } \\
\hline \multicolumn{5}{|c|}{ Index finger abduction } \\
\hline $110 \%$ AMT & $1.5 \pm 1.1$ & $1.2 \pm 0.7$ & $0.92 \pm 0.4$ & $p=0.30$ \\
\hline $120 \%$ AMT & $3.4 \pm 2.2$ & $2.2 \pm 1.9$ & $1.4 \pm 0.9$ & $p=0.045$ \\
\hline $150 \%$ AMT & $7.4 \pm 3.3$ & $3.0 \pm 2.4$ & $2.3 \pm 1.5$ & $p<0.001$ \\
\hline$p$-values & $p<0.001$ & $p=0.002$ & $p=0.001$ & \\
\hline \multicolumn{5}{|l|}{ Precision grip } \\
\hline $110 \%$ AMT & $1.2 \pm 0.9$ & $1.0 \pm 0.6$ & $0.90 \pm 0.4$ & $p=0.67$ \\
\hline $120 \%$ AMT & $2.7 \pm 1.7$ & $1.8 \pm 1.6$ & $1.3 \pm 0.9$ & $p=0.11$ \\
\hline $150 \%$ AMT & $6.0 \pm 2.6$ & $2.5 \pm 2.1$ & $2.2 \pm 1.5$ & $p<0.001$ \\
\hline$p$-values & $p<0.001$ & $p=0.003$ & $p=0.001$ & \\
\hline
\end{tabular}

adhesive $\mathrm{Ag}-\mathrm{AgCl}$ electrodes fixed to the skin behind the mastoid process and by using a double cone magnetic coil over the back of the head (Taylor and Gandevia, 2004). The stimulation intensity was set to elicit a CMEP in the FDI muscle of $\sim 5 \%$ of the maximal motor response (M-max) during index finger abduction [electrical stimulation: controls $=273.3 \pm 33.8 \mathrm{~mA}, n=7, \mathrm{SCI}_{\mathrm{Bac}}=301 \mathrm{~mA}, n=1, \mathrm{SCI}_{\mathrm{No}-\mathrm{Bac}}=300$ $\mathrm{mA} n=1$; magnetic stimulation: $\mathrm{SCI}_{\mathrm{Bac}}=100 \pm 0 \%$ of maximal stimulator output (MSO), $n=2, \mathrm{SCI}_{\mathrm{No}-\mathrm{Bac}}=90 \%$ of MSO, $\left.n=1\right]$. Fifteen CMEPs were tested during index finger abduction and 15 CMEPs during precision grip in a randomized order.

F-waves. Motoneuron excitability (reflected by F-wave amplitude and persistence) was measured in controls $(n=9), \operatorname{SCI}_{\mathrm{Bac}}(n=7)$, and $\mathrm{SCI}_{\text {No-Bac }}(n=6)$ using supramaximum stimulus intensity to the ulnar nerve at the wrist (200 $\mu$ s pulse duration, DS7A; Digitimer). The anode and cathode were $3 \mathrm{~cm}$ apart and $1 \mathrm{~cm}$ in diameter with the cathode positioned proximally. The stimuli were delivered at $1 \mathrm{~Hz}$ at an intensity of $120 \%$ of the M-max. For each trial, we quantified peak-to-peak amplitude (expressed relative to the M-max) and F-wave persistence (number of F-waves present in each set). If the F-wave was not present, an amplitude of zero was included in the mean (Butler and Thomas, 2003; Bunday and Perez, 2012a). The same result in all groups was observed whether the zero F-wave amplitudes were included in the analysis or not. Thirty F-waves were tested in each condition. Measurements were repeated four to five times during index finger abduction and precision grip in a randomized order.

svEMG. TMS at an intensity below MEP threshold applied during voluntary contraction has been shown to suppress EMG activity (Davey et al., 1994; Petersen et al., 2001). It is thought that the svEMG activity reflects activation of inhibitory mechanisms within the motor cortex (Butler et al., 2007). The svEMG was first measured in controls $(n=16)$, $\operatorname{SCI}_{\mathrm{Bac}}(n=9)$, and $\mathrm{SCI}_{\mathrm{No}-\mathrm{Bac}}(n=10)$ in the FDI muscle during the index finger abduction task and later in the precision grip task using the same stimulus intensity. At first, the stimulus intensity was increased in small steps until the svEMG was present without evoking a short-latency facilitation during index finger abduction. Based on previous results, we started the test with intensities 10 or $20 \%$ below the AMT (Perez et al., 2007). If facilitation was observed during precision grip, the intensity was reduced and the test was repeated in both tasks using this new stimulus intensity. The onset of the svEMG was determined by visual inspection and by using a horizontal cursor showing the mean rectified EMG before the TMS artifact as a reference. svEMG onset was defined as the time point when the mean rectified EMG activity dropped below the mean (minimal duration of $10 \mathrm{~ms}$ ) and the end of the svEMG as the time point when the EMG returned through this level. The area of the svEMG was measured between the onset and offset of the svEMG using following formula: $\mathrm{svEMG}$ area $=[($ background mean rectified $\mathrm{EMG} \times \mathrm{svEMG}$ duration) - au_svEMG], where background mean rectified EMG is the mean amplitude rectified EMG for 100 ms prestimulus period and 
au_svEMG is the area under the rectified svEMG. After that, the svEMG area was normalized against the prestimulus EMG level [svEMG area normalized to prestimulus EMG $=$ svEMG area/(background mean rectified EMG $\times$ mean duration of svEMG); Trompetto et al., 2004]. Mean duration (controls $=25.8 \pm 11.7 \mathrm{~ms}, \mathrm{SCI}_{\mathrm{Bac}}=28.0 \pm 7.8 \mathrm{~ms}$, and $\left.\mathrm{SCI}_{\mathrm{No}-\mathrm{Bac}}=30.3 \pm 10.9 \mathrm{~ms} ; F_{(2,33)}=0.59, p=0.56\right)$ and latency (controls $=32.4 \pm 5.2 \mathrm{~ms}, \mathrm{SCI}_{\mathrm{Bac}}=39.8 \pm 6.3 \mathrm{~ms}$, and $\mathrm{SCI}_{\mathrm{No}-\mathrm{Bac}}=36.9 \pm$ $\left.5.8 \mathrm{~ms} ; F_{(2,33)}=5.59, p=0.008\right)$ of svEMG were measured in both tasks in each group. The interstimulus interval for TMS pulses was $1 \mathrm{~s}$. Seventy-five trials were tested in each condition.

Data analysis. Normal distribution was tested by the Shapiro-Wilk's test and homogeneity of variances by the Levene's test of equality and Mauchly's test of sphericity. When sphericity could not be assumed, the Greenhouse-Geisser correction statistic was used. Repeated-measures ANOVAs were performed to determine the effect of task (precision grip, index finger abduction), group (controls, $\mathrm{SCI}_{\mathrm{Bac}}, \mathrm{SCI}_{\mathrm{No}-\mathrm{Bac}}$ ), and intensity $(110 \%, 120 \%, 150 \%)$ on MEP ratio (MEP size during precision grip as a percentage of index finger abduction), background mean EMG amplitude, and mean rectified EMG (\% MVC) activity in the FDI and APB muscles. Bonferroni's post hoc analysis was used to test for significant comparisons between intensities. Gabriel's post hoc analysis was used to test for significant comparisons between groups. When equal variances between groups could not be assumed, the Games-Howell test was used. Repeated-measures ANOVAs were also performed to determine the effect of task (precision grip, index finger abduction) and group (controls, $\left.\mathrm{SCI}_{\mathrm{Bac}}, \mathrm{SCI}_{\mathrm{No}-\mathrm{Bac}}\right)$ on svEMG, F-wave persistence and amplitude, and slope between MEP size and TMS intensity. Additional repeatedmeasures ANOVAs and $t$ tests were performed on each group separately. Nonparametric two-way ANOVA by ranks was performed to determine the effect of task and group on CMEPs. One-way ANOVAs were also performed to test the effect of group on AMT, TMS intensity $(110 \%$, $120 \%, 150 \%$ ), MEP-max, M-max, svEMG intensity, response latency, and CMEP intensity. Pearson correlation analysis was used as needed. Significance was set at $p<0.05$. Group data are presented as the means \pm $\mathrm{SD}$ in the text.

\section{Results}

EMG

Figure 2 shows the group mean rectified EMG activity as a percentage of MVC in the FDI and APB muscles during precision grip and index finger abduction in all groups. Each group was instructed to perform a natural precision grip by grasping a small cylinder between the thumb and index finger. Note that mean rectified EMG activity in both muscles was expressed as a percentage of the activity during an MVC and was measured in the $100 \mathrm{~ms}$ period before TMS stimulus artifact during testing of MEPs at increasing TMS intensities.

Repeated-measures ANOVA showed a significant effect of group $\left(F_{(2,31)}=9.7, p=0.001\right)$, but not task $\left(F_{(1,30)}=1.5, p=\right.$ $0.21)$ nor in their interaction $\left(F_{(2,30)}=1.7, p=0.19\right)$ on FDI mean rectified EMG activity. Post hoc testing showed that EMG activity was increased in $\mathrm{SCI}_{\mathrm{Bac}}(p=0.001)$ and $\mathrm{SCI}_{\mathrm{No}-\mathrm{Bac}}(p=$ $0.01)$ compared with controls. No differences were found between patient groups $(p=0.95)$. Although patients overall exerted more EMG activity than controls in both tasks, each group of subjects maintained similar EMG activity in the FDI muscle during precision grip and index finger abduction $\left(F_{(1,30)}=1.5\right.$, $p=0.21$.

During index finger abduction, controls $\left(F_{(1,14)}=8.6, p=\right.$ 0.01; Fig. $2 A), \operatorname{SCI}_{\mathrm{Bac}}\left(F_{(1,9)}=29.5, p<0.001\right.$; Fig. $\left.2 C\right)$, and $\mathrm{SCI}_{\text {No-Bac }}\left(\mathrm{F}_{(1,78}=5.9, p=0.04\right.$; Fig. $\left.2 E\right)$ exerted more EMG activity in the FDI compared with the APB at all TMS intensities tested. In an additional experiment, healthy controls were asked to increase the EMG activity during index finger abduction to match the EMG exerted by SCI participants $\left(F_{(1,26)}=1.2, p=\right.$ 0.33 ; Fig. $2 G$ ). During precision grip, the strategy used by controls
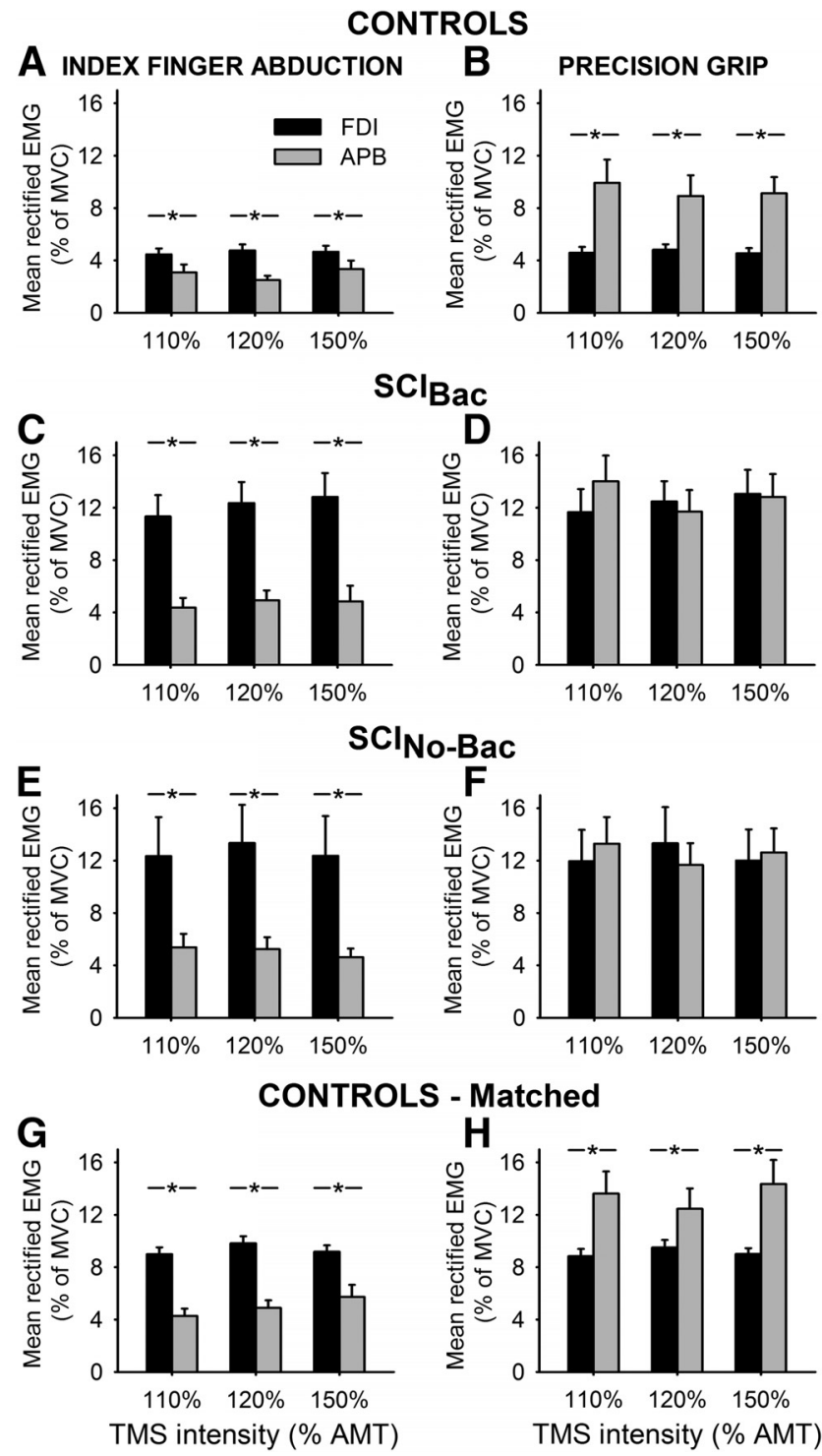

Figure 2. EMG recordings. Group data show the mean rectified EMG activity in the FDI (black bars) and $\mathrm{APB}$ (gray bars) in healthy controls $(\boldsymbol{A}, \boldsymbol{B}, n=15), \mathrm{SCl}$ patients taking baclofen $(\boldsymbol{C}, \boldsymbol{D}$ $\left.\mathrm{SCl}_{\mathrm{Bac}^{\prime}} n=10\right)$ and in patients who never took baclofen $\left(\boldsymbol{E}, \boldsymbol{F}, \mathrm{SCl}_{\mathrm{No}^{-B a}{ }^{\prime}} n=11\right)$ during index finger abduction (left column) and precision grip (right column). Note that we included 12 participants in the $\mathrm{SCl}_{\mathrm{Bac}}$ group and 10 of them participated in most measurements. The additional 2 patients were included only for the svEMG test. Mean rectified EMG activity in both muscles was obtained 100 ms before TMS stimulus artifact during testing of MEPs at increasing TMS intensities. The abscissa shows the TMS stimulus intensity used during testing (110\%, $120 \%$, and $150 \%$ of AMT). The ordinate shows the mean rectified EMG activity as a percentage of the MVC in each muscle tested. Note that EMG activity in the FDI muscle was matched during index finger abduction and precision grip in all groups. Also note that the EMG strategy used by controls and patients during precision grip was different. Here, control subjects activated the APB to a larger extent than the FDI muscle, whereas both groups of patients activated both muscles to a similar extent. Additional testing showed that control subjects were able to increase EMG activity to match EMG levels in patients during both tasks ( $\boldsymbol{G}, \boldsymbol{H}$; controls matched, $n=11)$. Error bars indicate SE. * $p<0.05$.

and patients was different. Here, controls exerted more EMG activity in the APB compared with the FDI at all TMS intensities tested $\left(F_{(1,14)}=15.2, p=0.002\right.$; Fig. $\left.2 B\right)$ regardless of whether EMG activity was increased to match the patients $\left(F_{(1,13)}=9.6\right.$, $p=0.009$; Fig. $2 H) . \mathrm{SCI}_{\mathrm{Bac}}\left(F_{(1,8)}=2.7, p=0.14\right.$; Fig. $\left.2 D\right)$ and $\mathrm{SCI}_{\mathrm{No}-\mathrm{Bac}}\left(F_{(1,8)}=0.3, p=0.47\right.$; Fig. $\left.2 F\right)$ exerted a similar amount of EMG activity in the APB and FDI at all TMS intensities tested. 


\section{CONTROLS}

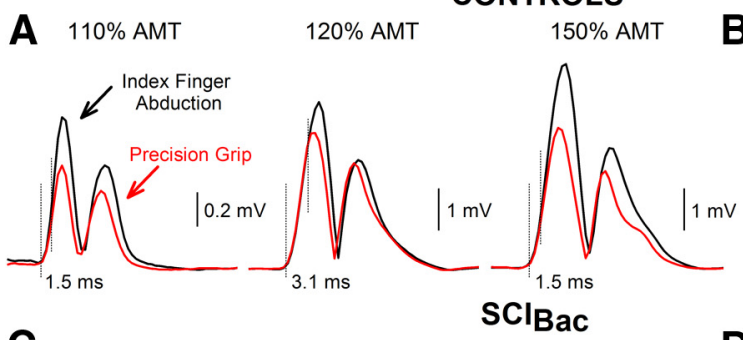

C $110 \%$ AMT

$120 \%$ AMT

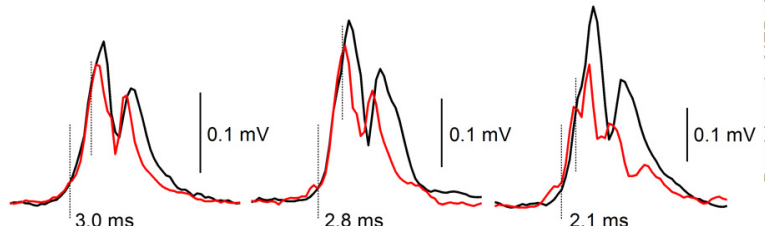

$2.1 \mathrm{~ms}$

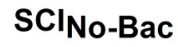

E $\quad 110 \%$ AMT

$120 \%$ AMT

$150 \%$ AM
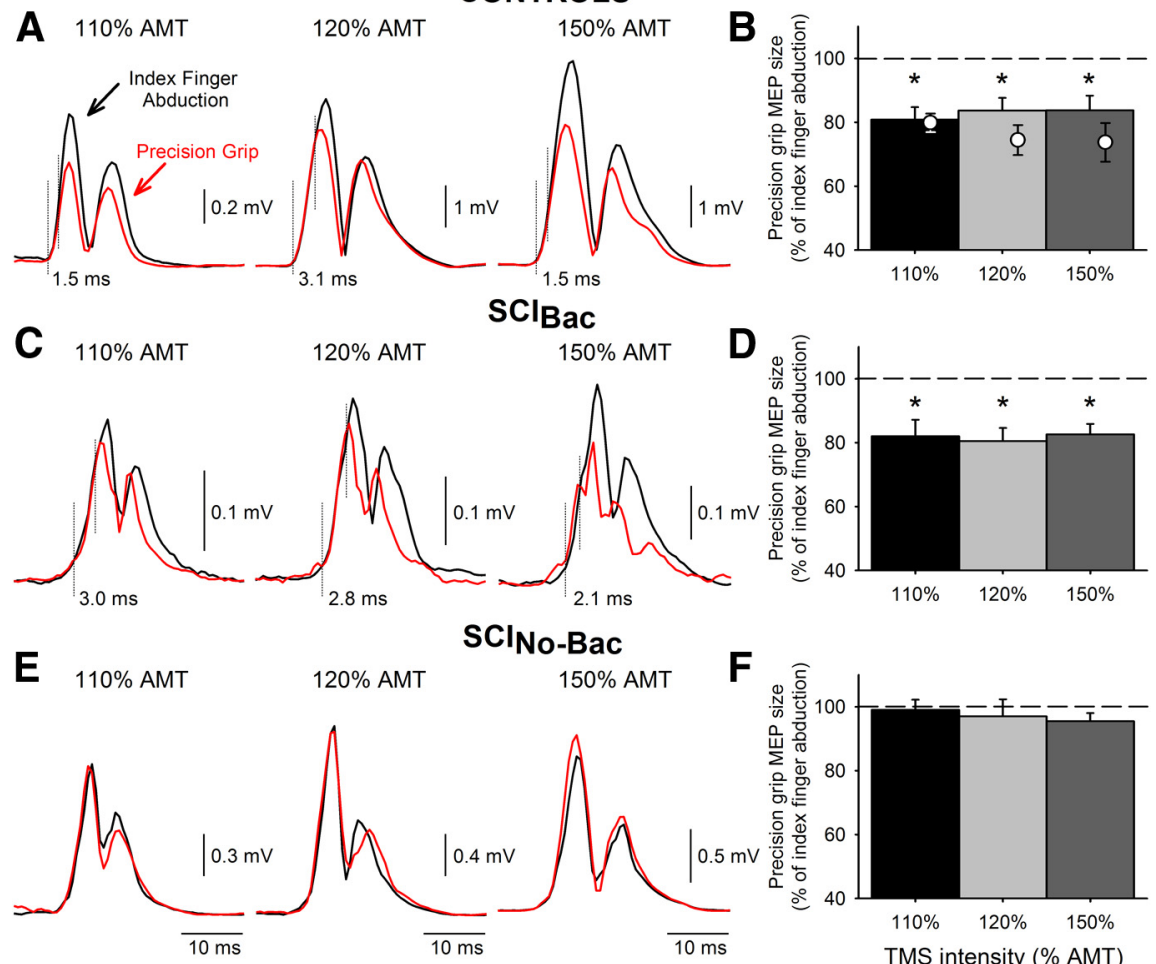

Figure 3. MEPs elicited by TMS. MEPs tested in the FDI muscle in a representative control subject ( $\boldsymbol{A}$, upper traces) and in patients with $\mathrm{SCl}_{\mathrm{Bac}}\left(\boldsymbol{C}\right.$, middle traces) and $\mathrm{SCl}_{\mathrm{No}-\mathrm{Bac}}(\boldsymbol{E}$, lower traces) during precision grip (red traces) and index finger abduction (black traces). Traces show the average 20 rectified MEPs on each condition tested at increasing TMS intensities. The dotted vertical lines indicate the approximate time of MEP onset and when MEP responses diverge. Group data are shown in bar graphs ( $\boldsymbol{B}$, controls, $\left.n=15 ; \boldsymbol{D}, \mathrm{SCl}_{\mathrm{Bac}}, n=10 ; \boldsymbol{F}, \mathrm{SCl}_{\mathrm{No}-\mathrm{Bac}}, n=11\right)$. The abscissa shows all TMS intensities tested $(110 \%, 120 \%$, and $150 \%)$. The ordinate shows the magnitude of the MEP size during precision grip expressed as a percentage of the MEP tested during index finger abduction. The horizontal dashed line represents the size of the MEP during index finger abduction. Note that MEP size decreased during precision grip compared with index finger abduction in controls and in $\mathrm{SCl}_{\mathrm{Bac}}$, but remained unchanged in $\mathrm{SCI}_{\mathrm{No}-\mathrm{Bac}}$ at all TMS intensities tested. Also note that, in control subjects, MEP size decreased during precision grip compared with index finger abduction at all TMS intensities at matched level of EMG exerted by patients ( $\boldsymbol{B}$, open circles, $n=11$ ). Error bars indicate SE. * $p<0.05$.

\section{MEPs}

Figure 3 illustrates rectified MEPs from representative participants tested during precision grip and index finger abduction at increasing TMS intensities. Note that the size of MEPs in the FDI muscle decreases during precision grip compared with index finger abduction at all stimulus intensities in controls and $\mathrm{SCI}_{\mathrm{Bac}}$, but not in $\mathrm{SCI}_{\mathrm{No}-\mathrm{Bac}}$.

Repeated-measures ANOVA showed a significant effect of $\operatorname{task}\left(F_{(1,30)}=37.9, p<0.001\right)$, group $\left(F_{(2,30)}=4.5, p=0.01\right)$, and their interaction $\left(F_{(2,30)}=4.5, p=0.01\right)$, but not of intensity $\left(F_{(2,60)}=0.2, p=0.84\right)$ on FDI MEP ratio. Post hoc testing showed a significant decrease in MEP size in controls $(110 \%$ $\mathrm{AMT}=79.2 \pm 16.0 \%, 120 \% \mathrm{AMT}=82.1 \pm 3.9 \%, 150 \% \mathrm{AMT}=$ $84.5 \pm 2.6 \% ; F_{(1,14)}=27.2, p<0.001$; Fig. $\left.3 B\right)$ and $\mathrm{SCI}_{\mathrm{Bac}}(110 \%$ $\mathrm{AMT}=82.0 \pm 17.0 \%, 120 \% \mathrm{AMT}=80.5 \pm 13.2 \%, 150 \%$ $\mathrm{AMT}=82.6 \pm 10.8 \% ; F_{(1,9)}=21.5, p=0.001$; Fig. $\left.3 D\right)$ during precision grip compared with index finger abduction. Note that the first part of the MEP response remained similar in size during precision grip and index finger abduction at all TMS intensities tested (controls: $2.2 \pm 0.8 \mathrm{~ms}$, range $0.9-3.8 ; \mathrm{SCI}_{\mathrm{Bac}}: 2.4 \pm 0.9$ ms, range 0.9-4.3; Figure $3 A, C$, vertical dashed line), whereas the later portion of the MEP response decreased during precision grip compared with index finger abduction. In contrast, FDI MEP size remained similar during both tasks in $\mathrm{SCI}_{\mathrm{No}-\mathrm{Bac}}(110 \%$
$\mathrm{AMT}=99.0 \pm 9.6 \%, 120 \% \mathrm{AMT}=$ $96.9 \pm 16.0 \%, 150 \%$ AMT $=95.5 \pm$ $7.7 \% ; F_{(1,2)}=1.6, p=0.24$; Fig. $\left.3 F\right)$. Because background FDI EMG activity was different across groups (Fig. $2 A-F$ ), MEPs were also tested at all intensities by increasing FDI activity in control subjects to match the level of EMG exerted by patients $\left(F_{(2,26)}=0.33, p=0.72\right)$. As before, we found that MEPs ratio decreased in controls during precision grip compared with index finger abduction $\left(F_{(1,10)}=\right.$ $18.56, p=0.002$; Fig. $3 B$, open circles). A positive correlation was found between SWMT sensory scores and MEP size during precision grip in $\mathrm{SCI}_{\mathrm{No}-\mathrm{Bac}}(r=0.77$, $p=0.02)$, but not in $\mathrm{SCI}_{\mathrm{Bac}}(r=-0.46$, $p=0.21)$.

To further understand differences in MEP size across groups, we examined the effect of increasing stimulus intensity on raw MEP size in each task separately. Figure 4 illustrates MEPs from representative participants during index finger abduction and precision grip. Note that, in both tasks, MEP size increased pronouncedly with increasing TMS intensity the control subject, but to a lesser extent in patients. Repeated-measures ANOVA showed a significant effect of intensity $\left(\mathrm{F}_{(1.5,46.1)}=36.2\right.$, $p<0.001)$, group $\left(F_{(2,30)}=7.9, p=0.002\right)$, and their interaction $\left(\mathrm{F}_{(3.0,45.2)}=20.4, p<\right.$ 0.001 ) on MEP size in the index finger abduction task. A similar result was found during precision grip (intensity: $F_{(1.5,46.3)}$ $=38.0, p<0.001$; group: $F_{(2,30)}=6.1, p=$ 0.006; interaction: $F_{(3.1,46.3)}=9.5, p<$ 0.001). Post hoc tests for index finger abduction and precision grip revealed that, at increasing stimulus intensity, MEP sizes in control subjects were larger than $\mathrm{SCI}_{\mathrm{Bac}}$ and $\mathrm{SCI}_{\mathrm{No} \text {-Bac }}$ but similar across patient groups (Table 2). Repeated-measures ANOVA revealed a significant effect of group $\left(F_{(1,32)}=16.1, p<0.001\right)$, but not task $\left(F_{(1,32)}=0.21, p=0.65\right)$ or their interaction $\left(F_{(2,32)}=0.28, p=\right.$ $0.07)$ on the slope of the linear regression line between MEP size and TMS intensity. Post hoc tests for both tasks revealed that the slope was significantly steeper in controls compared with $\mathrm{SCI}_{\mathrm{Bac}}$ (index finger abduction, $p=0.002$; precision grip, $p<0.001$; Fig. $4 A-D$ ) and $\mathrm{SCI}_{\mathrm{No}-\mathrm{Bac}}$ (index finger abduction, $p<0.001$; precision grip, $p<0.001$; Fig. $4 A-D)$. The slope was similar across patient groups in the index finger abduction $(p=0.89)$ and precision grip $(p=0.99)$ tasks.

\section{CMEPs}

To examine the contribution of subcortical pathways to the changes observed in MEP size, we measured CMEPs in the FDI muscle during both tasks. Figure 5 illustrates an example of rectified CMEPs in the FDI muscle in representative participants. Note that CMEP size decreased during precision grip compared with index finger abduction in the control and $\mathrm{SCI}_{\mathrm{Bac}}$, but not in $\mathrm{SCI}_{\mathrm{No}-\mathrm{Bac}}$. The latency of CMEPs was significantly shorter than MEPs elicited by TMS (controls $=18.5 \pm 0.8 \mathrm{~ms}, 21.7 \pm 0.8 \mathrm{~ms}$, respectively; $\mathrm{SCI}_{\mathrm{Bac}}=21.4 \pm 1.4 \mathrm{~ms}, 25.2 \pm 1.0 \mathrm{~ms}$, respectively; 
$\mathrm{SCI}_{\mathrm{No}-\mathrm{Bac}}=21.8 \pm 0.2 \mathrm{~ms}, 25.3 \pm 0.4 \mathrm{~ms}$, respectively; $\left.F_{(1,8)}=63.8, p<0.001\right)$, indicating that the stimulation activated corticospinal axons bypassing the motor cortex.

A nonparametric 2-way ANOVA by ranks showed a significant effect of task $\left(F_{(1,9)}=37.9, p<0.001\right)$, group $\left(F_{(2,9)}=\right.$ $7.5, p=0.01)$, and their interaction $\left(F_{(2,9)}\right.$ $=7.5, p=0.01)$ on CMEP size. Post hoc comparisons revealed that FDI CMEPs decreased during precision grip compared with index finger abduction in controls $(78.5 \pm 11.2 \% ; p<0.01$; Fig. $5 A, B)$ and $\mathrm{SCI}_{\mathrm{Bac}}(71.5 \pm 2.5 \% ; p<0.01$; Fig. $5 C, D)$, but not in $\mathrm{SCI}_{\mathrm{No}-\mathrm{Bac}}(97.1 \pm 5.0 \%$; $p=0.57$; Fig. $5 E, F)$. In control subjects (1.3 $\pm 0.8 \mathrm{~ms}$, range $0.5-2.4)$ and in SCIBac $(1.4 \pm 0.3 \mathrm{~ms}$, range $1.0-1.6)$, the first part of the CMEP remained similar in size during precision grip and index finger abduction, whereas the later portion of the CMEP decreased during precision grip compared with index finger abduction. Background EMG amplitude was similar across tasks $\left(F_{(1,9)}=0.46, p=0.45\right)$ and groups $\left(F_{(1,9)}=0.91, p=0.43\right)$.

\section{F-waves}

We measured spinal motoneuron excitability by testing the F-wave amplitude and persistence in the FDI muscle. The maximum $\mathrm{M}$-wave was larger in controls $(21.3 \pm 3.1 \mathrm{mV})$ than in $\mathrm{SCI}_{\mathrm{Bac}}(13.9 \pm$ $5.7 \mathrm{mV} ; p=0.01)$ and $\mathrm{SCI}_{\mathrm{No}-\mathrm{Bac}}(13.4 \pm$ $6.4 \mathrm{mV} ; p=0.01)$. Figure 6 illustrates F-waves in the FDI muscle during precision grip and index finger abduction in representative subjects. Note the similarity in F-wave amplitude and persistence across tasks in all groups.

Repeated-measures ANOVA revealed no effect of task $\left(F_{(1,20)}\right.$ $=1.0, p=0.36)$, group $\left(F_{(2,20)}=1.7, p=0.2\right)$, or their interaction $\left(F_{(2,20)}=1.7, p=0.2\right)$ on F-wave amplitude. F-wave amplitude was similar across tasks in controls (112.5 $\pm 17.6 \%$; Fig. $6 A, B), \mathrm{SCI}_{\mathrm{Bac}}(101.4 \pm 7.9 \%$; Fig. $6 C, D)$, and $\mathrm{SCI}_{\mathrm{No}-\mathrm{Bac}}(96.4 \pm$ 4.8\%; Fig. $6 E, F)$. Similarly, when comparing F-wave persistence, we found no effect of task $\left(F_{(1,9)}=1.6, p=0.23\right)$, group $\left(F_{(2,9)}=\right.$ $3.5, p=0.10)$, or their interaction $\left(F_{(2,9)}=3.5, p=0.10\right)$. F-wave persistence was similar during precision grip compared with index finger abduction in controls (110.4 $\pm 11.8 \%$; Fig. $6 A, B), \mathrm{SCI}_{\mathrm{Bac}}$ $(110.2 \pm 12.3 \%$; Fig. $6 C, D)$, and $\mathrm{SCI}_{\mathrm{No}-\mathrm{Bac}}(91.5 \pm 1.7 \%$; Fig. $6 E, F)$.

\section{svEMG}

To determine the contribution of intracortical pathways to the changes observed in the MEP size, we measured the svEMG in the FDI muscle during both tasks. Figure 7 illustrates mean rectified EMG in the FDI muscle during subthreshold TMS in representative subjects during precision grip and index finger abduction. Note that the magnitude of svEMG decreases during precision grip compared with index finger abduction in all participants.

Repeated-measures ANOVA showed significant effect of task $\left(F_{(1,33)}=25.28, p<0.001\right)$, but not group $\left(F_{(2,33)}=0.95, p=\right.$ $0.39)$ or their interaction $\left(F_{(2,33)}=1.67, p=0.20\right)$ on the svEMG SE. ${ }^{*} p<0.05$.
$120 \%$ AMT
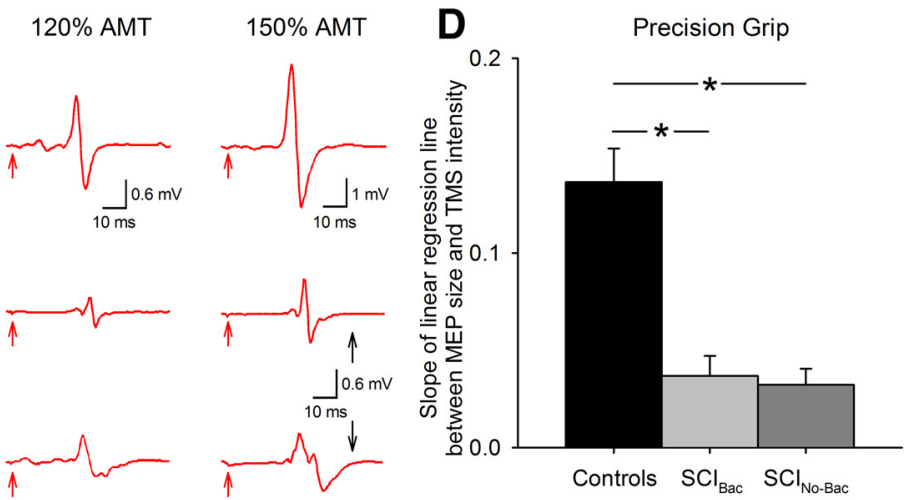

Controls $\mathrm{SCl}_{\mathrm{BaC}} \mathrm{SCl}_{\mathrm{No}-\mathrm{B}}$
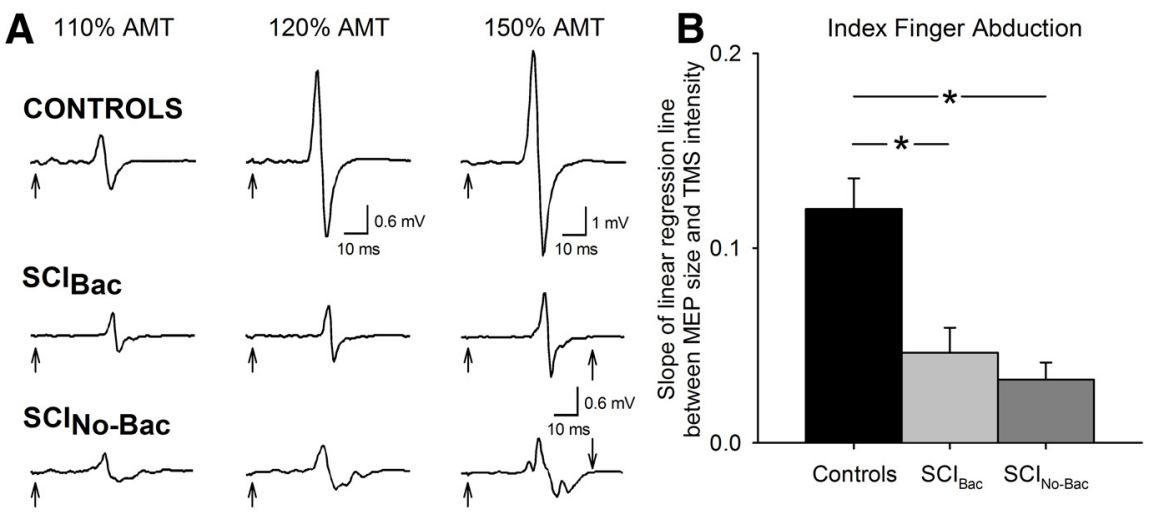

Figure 4. Effect of increasing stimulus intensity on MEP size. MEPs tested in the FDI muscle during index finger abduction $(\boldsymbol{A}$, increasing TMS intensities in the control subject, but to a lesser extent in patients. Group data are shown in separate graphs for intensities tested (110\%, 120\%, and 150\%). The ordinate shows the slope of the linear regression line between MEP size and TMS intensity. Note that the MEP slope was larger in control subjects compared with $\mathrm{SCI}_{\mathrm{Bac}}$ and $\mathrm{SCl}_{\mathrm{No}-\mathrm{Bac}}$ in both tasks. Error bars indicate

area. The svEMG area was decreased during precision grip compared with index finger abduction in controls (index finger abduction $=32.9 \pm 20.1 \%$, precision grip $=28.0 \pm 17.5, p=0.03$; Fig. $7 A, B$ ), $\mathrm{SCI}_{\mathrm{Bac}}$ (index finger abduction $=39.5 \pm 12.1 \%$, precision grip $=27.1 \pm 10.7 \%, p=0.02$; Fig. $7 C, D)$, and $\mathrm{SCI}_{\mathrm{No}-\mathrm{Bac}}$ (index finger abduction $=28.6 \pm 14.2 \%$, precision grip $=19.4 \pm$ $18.5 \%, p=0.02$; Fig. $7 E, F)$. Background rectified EMG area was similar across tasks $\left(F_{(1,33)}=4.9, p=0.49\right)$ and groups $\left(F_{(1,33)}=2.5\right.$, $p=0.78)$.

\section{Discussion}

We investigated the contribution of subcortical pathways to the control of a precision grip in humans with subcortical damage due to incomplete cervical SCI. We demonstrate that motor cortical and cervicomedullary MEPs are reduced during precision grip compared with index finger abduction in control subjects, but remain unchanged in patients with SCI. However, using the GABAb receptor agonist baclofen long-term ( $\sim 5$ years $)$ reduced the size of motor cortical and cervicomedullary MEPs during precision grip in patients with SCI to similar levels as controls. In contrast, we could find no evidence that there was any difference between groups in our measures of intracortical inhibition or spinal motoneuron excitability. Our findings indicate that the control of precision grip in humans involves premotoneuronal subcortical mechanisms, which are lacking after SCI and restored 


\section{CONTROLS}

A

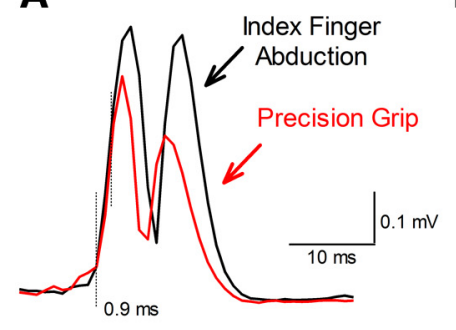

SClBac
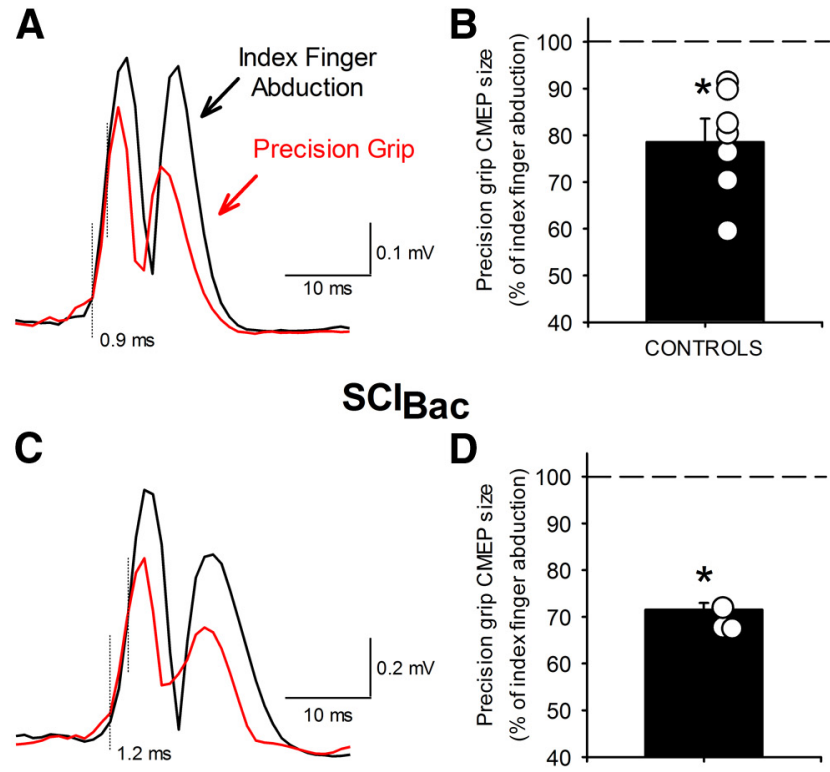

D

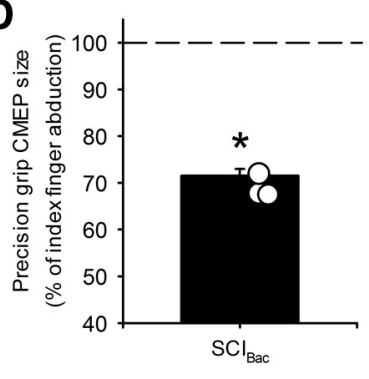

SClNo-Bac

E

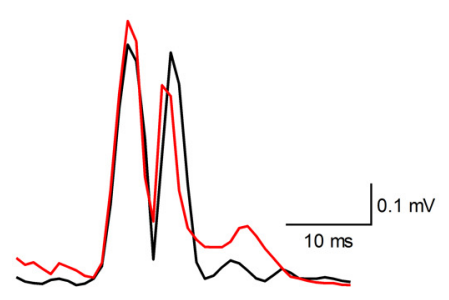

$\mathbf{F}$

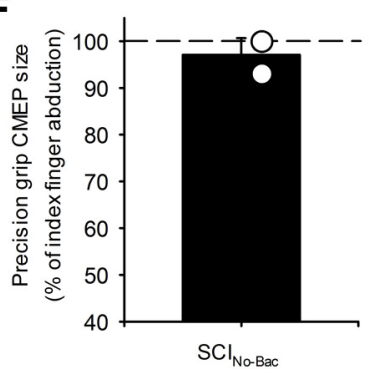

Figure 5. MEPs elicited by cervicomedullary stimulation. Raw EMG data in three representative subjects $(\boldsymbol{A}, \boldsymbol{C}, \boldsymbol{E})$ showing CMEPs recorded from the FDI muscle during index finger abduction (black traces) and precision grip (red traces). Fifteen rectified traces were averaged in each set. The dotted vertical lines indicate the approximate time of CMEP onset and when CMEP responses diverge. In the graphs, the abscissa shows the groups tested ( $\boldsymbol{B}$, controls, $n=7 ; \mathbf{D}$, $\left.\mathrm{SCl}_{\mathrm{Ba},} n=3 ; \boldsymbol{F}_{,} \mathrm{SCl}_{\mathrm{No-Bac},} n=2\right)$ and the ordinate shows the size of CMEPs during precision grip as a percentage of the CMEPs tested during index finger abduction. The horizontal dashed line represents the size of the CMEPs during index finger abduction. Data from individual subjects in each group are shown in open circles. Note that the size of CMEPs decreased during precision grip compared with index finger abduction in controls and in $\mathrm{SC}_{\mathrm{Bac}}$, but remained unchanged in $\mathrm{SCI}_{\mathrm{No}-\mathrm{Bac}}$. Error bars indicate SE. ${ }^{*} p<0.05$.

by long-term use of baclofen. Because the MEP suppression began 1-3 ms after MEP onset, it is possible that disynaptic or polysynaptic spinal pathways were involved. We propose that activity evoked in the corticospinal tract by TMS of either cortex or brainstem activates spinal motoneurons monosynaptically and via spinal interneurons. We argue that, during precision grip, descending and/or peripheral systems increase GABAb-ergic inhibition of the interneuronal pathways, thereby reducing the amplitude of the MEP that is recorded.

\section{Corticospinal drive contributes to the control of human precision grip}

Our results in control subjects agree with previous findings showing that the size of MEPs in an intrinsic finger muscle is reduced during a hand grip compared with index finger abduction at matched levels of EMG activity (Datta et al., 1989). They also
CONTROLS
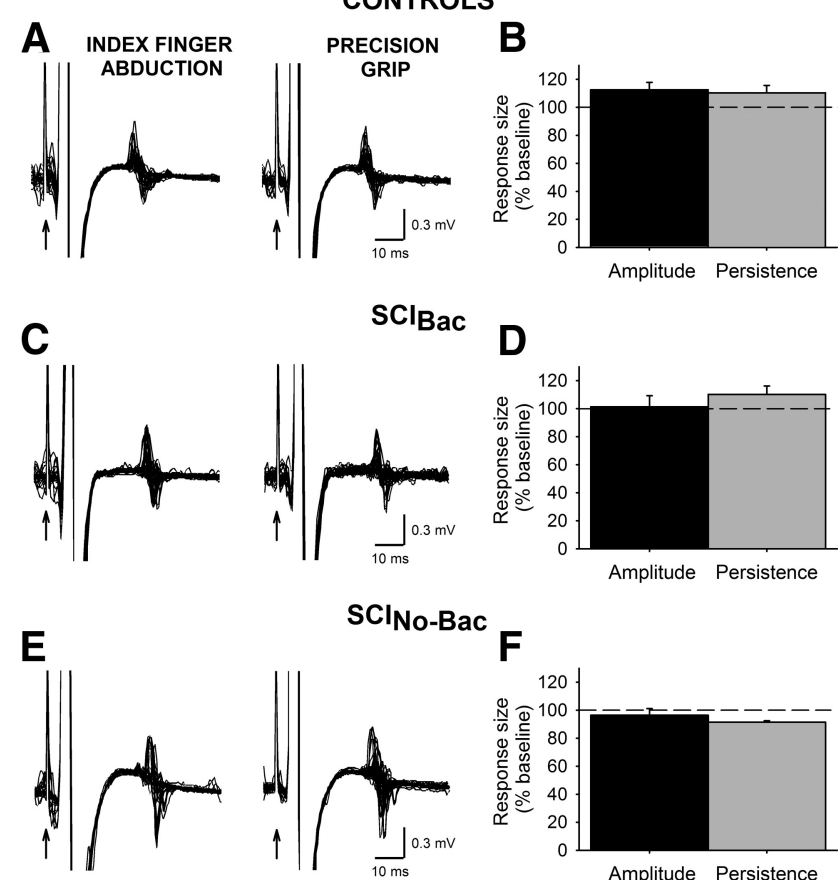

SClBac
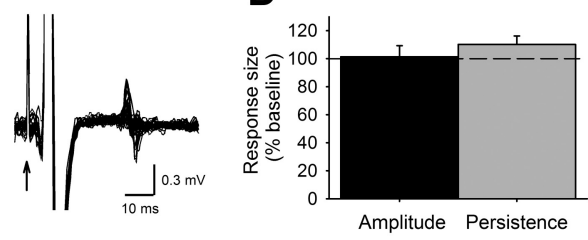

SClNo-Bac
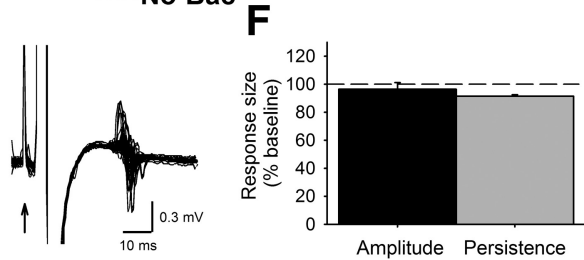

Figure 6. F-waves. M-waves and F-waves were recorded from the FDI muscle in three representative subjects $(\boldsymbol{A}, \boldsymbol{C}, \boldsymbol{E})$ during index finger abduction (left column) and precision grip (right column). Thirty traces are shown in each set. The time of stimulation is indicted by black arrows. Group data are shown in the graphs ( $\boldsymbol{B}$, controls, $n=9 ; \mathbf{D}, \mathrm{SCl}_{\mathrm{Bac}}, n=7 ; \boldsymbol{F}, \mathrm{SCl}_{\mathrm{No}-\mathrm{Bac}}$ $n=6$ ). The abscissa shows measurements tested: $F$-wave amplitude (black bars) and F-wave mean persistence (gray bars). The ordinate shows each measurement during precision grip as a percentage of the measurements tested during index finger abduction. The horizontal dashed line represents the size of the $\mathrm{F}$-wave measurements during index finger abduction. Note that F-wave persistence and mean amplitude remained similar during precision grip and index finger abduction in all groups. Error bars indicate SE. ${ }^{*} p<0.05$.

agree with studies showing that MEP size decreases during a task involving muscle coactivation compared with an isolated voluntary contraction (Aimonetti et al., 2002; Perez et al., 2007). Both primate and human experiments have suggested that different populations of corticospinal cells are responsible for the descending control during coactivation of muscles (Humphrey and Reed, 1983; Fetz and Cheney, 1987; Nielsen and Kagamihara, 1993; Johannsen et al., 2001). Muscle coactivation is a strategy used by the CNS to stabilize a joint during unpredictable external perturbations and during motor learning (Llewellyn et al., 1990; Nielsen and Kagamihara, 1993; Osu et al., 2002). A precision grip of a small object, as the one used in our study, might require tighter central control of finger muscles to maintain a stable pattern, which might benefit from a decrease in corticospinal excitability (Perez et al., 2007). Two other studies showed that the size of MEPs increases during precision grip compared with index finger abduction (Flament et al., 1993; Kouchtir-Devanne et al., 2012). The differences with our results are likely due to differences in methodology. In the previous studies, measurements were taken while subjects were grasping a cylinder $\sim 40-60 \mathrm{~mm}$ in diameter, whereas we used a cylinder of $6 \mathrm{~mm}$. EMG synchronization between thumb and index finger muscles occurs more frequently and is larger during grasping of a wider compared with a smaller object (Huesler et al., 1998). Because synchronization between EMG signals is thought to indicate common drive to two muscles from corticospinal inputs (Baker, 2007), strong synchronization may reflect increases in corticospinal output (Farmer et al., 1993). 


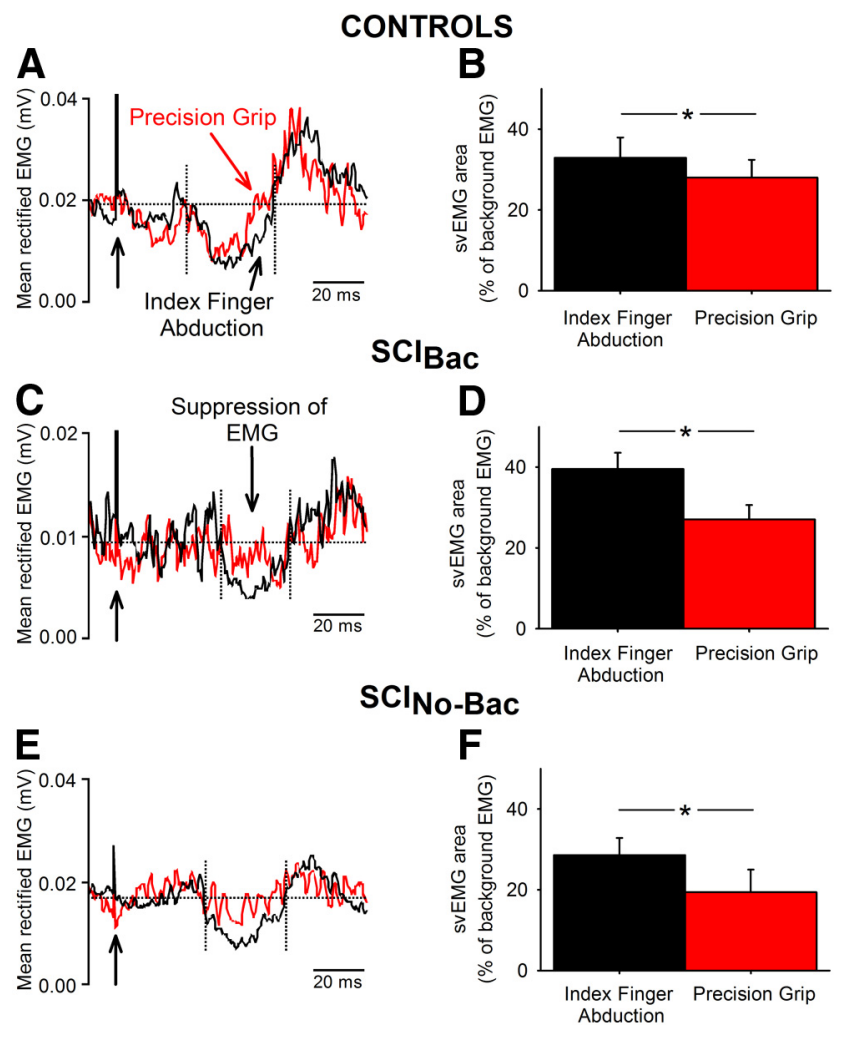

Figure 7. svEMG. Raw EMG data in a representative control subject ( $\boldsymbol{A}$, top traces) and in $\mathrm{SCl}_{\mathrm{Bac}}\left(\boldsymbol{C}\right.$, middle traces) and $\mathrm{SCl}_{\mathrm{No}-\mathrm{Bac}}(\boldsymbol{E}$, bottom traces) showing the SvEMG elicited by subthreshold TMS recorded in the FDI muscle during index finger abduction (black traces) and precision grip (red traces). Seventy-five traces were averaged in each set. The time of stimulation is indicated by black arrows on the left side. The onset and offset of the svEMG is shown between broken lines. Notice that all subjects shows less inhibition of the EMG during precision grip compared with index finger abduction. Graphs shows group data ( $\boldsymbol{B}$, controls, $n=16 ; \boldsymbol{D}$, $\mathrm{SCl}_{\mathrm{Bac}^{\prime}} n=9 ; \boldsymbol{F}, \mathrm{SCl}_{\mathrm{No}-\mathrm{Bac}} n=10$ ). The abscissa shows the conditions tested (index finger abduction, precision grip) and the ordinate shows the normalized area of the svEMG (see Materials and Methods). Note the decrease in the svEMG area during precision grip compared with index finger abduction in all groups. Error bars indicate SE. * $p<0.05$.

\section{Subcortical pathways contribute to the control of human precision grip}

Three lines of evidence support our argument that premotoneuronal circuits contribute to the control of precision grip. First, we found that the size of MEPs in the FDI muscle elicited by motor cortical and cervicomedullary stimulation were reduced during precision grip compared with index finger abduction in controls, but not in patients with SCI. MEPs evoked by TMS likely activate corticospinal axons transsynaptically, whereas MEPs evoked by CMEPs activate the axons of pyramidal tract cells in the subcortical white matter (Taylor and Gandevia, 2004). CMEPs are not influenced by the classical presynaptic inhibition (Nielsen and Petersen, 1994) and likely reflect changes occurring at subcortical levels (Petersen et al., 2010). Second, we found no changes in the amplitude and persistance of the F-waves during both tasks in all groups, suggesting that it is less likely that the decrease in MEP size was related to changes occurring at spinal motoneurons. In agreement, previous results showed no changes in motoneuronal excitability during motor tasks involving different selectivity in fine motor control of small finger muscles (Liepert et al., 1998). The interpretation of the F-wave results during voluntary activity is complex because voluntary orthodromic and antidromic impulses might collide, leaving some motor axons able to transmit an H-reflex to the muscle, so increases or decreases may be the result of changes in excitation or inhibition (Hultborn and Nielsen, 1995; Palleschi et al., 2014). However, this may not be a practical limitation in our study because subjects controlled excitability of the motoneuron pool by performing similar levels of voluntary activity across tasks. Furthermore, F-waves have shown to be sensitive to detect changes between SCI patients and controls across tasks (Butler and Thomas, 2003; Bunday and Perez, 2012a). Given that the CMEP size was decreased without changes in motoneuronal excitability, we propose that a premotoneuronal mechanism might represent a viable site for these changes to take place. The lack of changes during the first 1-3 ms of the MEP size suggest that the later suppression must have occurred through disynaptic or polysynaptic spinal pathways that mediate nonmonosynaptic corticospinal excitation of motoneurons (Mazevet et al., 1996). This possibility is also supported by our results in patients taking baclofen. Long-term use of baclofen restored the ability to decrease MEP size during a precision grip to similar levels as controls. Baclofen is a GABAb receptor agonist with effects on synaptic transmission that are largely attributed to its action on primary afferent terminals (Curtis et al., 1997) and last-order GABAergic interneurons (Quevedo et al., 1992). Therefore, excitability changes in interneurons and/or peripheral inputs converging on the motoneurons might contribute to the present results, although the precise duration and dose of baclofen needed for these changes to occur remains to be determined. Presynaptic inhibition at the terminal of Ia afferents increases during a motor task involving coactivation of muscles compared with isolated voluntary contraction (Nielsen and Kagamihara, 1993). Our results indicate that it is less likely that this is the source of the inhibition because the early part of the MEP was not reduced. However, we cannot exclude the possibility that presynaptic inhibition at the interneurons that carry corticospinal commands might have occurred. Presynaptic interneurons receive both supraspinal and peripheral inputs. The main supraspinal control acting on presynaptic interneurons is tonic depression originating from brainstem structures ( $\mathrm{Ru}-$ domin and Schmidt, 1999), which could represent a source for the CMEP suppression. Presynaptic interneurons also receive peripheral inputs from cutaneous afferents (Rudomin and Schmidt, 1999). Larger deficits in the monofilament tests of cutaneous sensibility in dermatome C6 resulted in lesser MEP suppression during precision grip in patients with SCI, which might have contributed to our results.

Third, we found a decrease in intracortical inhibition as measured by the svEMG during precision grip compared with index finger abduction in all groups. This result confirms the involvement of the motor cortex during human precision grip (Lang and Schieber, 2003, 2004). This also agrees with previous results showing that the modulation of intracortical inhibition during voluntary activity is not affected by baclofen intake in patients with SCI (Barry et al., 2013). The longer latency of the svEMG observed in patients compared with controls may indicate that either indirect or slow conducting corticospinal pathways were inhibited by the low-intensity TMS. During svEMG, the natural firing of corticospinal neurons is likely to be suppressed by intracortical inhibitory neurons lasting several tens of milliseconds and corticospinal drive is removed. Therefore, the decrease in svEMG area during precision grip might reflect increased or decreased contribution of the motor cortex by decreasing or increasing activity in intracortical neurons. If excitability changes in an indirect pathway contributes to the MEP suppression during precision grip, then it can be speculated that activity in direct corticospinal inputs increases in parallel to maintain muscle ac- 
tivity during this task, as reflected by the decrease in intracortical inhibition measured by the svEMG. Regardless of the interpretation of this result, our finding indicates that this is not the mechanism contributing to changes in MEP size during precision grip in controls and in patients taking baclofen.

\section{Functional considerations}

The present results expand our previous findings (Barry et al., 2013) by showing that long-term use of baclofen restores transmission in subcortical pathways controlling precision grip after SCI. This is important considering that $\sim 70 \%$ of SCI patients develop symptoms of spasticity and take baclofen (Rekand et al., 2012). A critical question is whether the restoration of these physiological outcomes has an impact on motor performance. Baclofen has been shown to have limited effects on voluntary motor output (Burke et al., 1971; Latash et al., 1989) and decreases contractile properties of motor units (Thomas et al., 2010) after SCI. We found that the EMG strategy used during precision grip and changes in MEP at increasing TMS intensities were similar across patients, suggesting that it is less likely that these physiological changes might have a direct impact on motor performance and corticospinal recruitment.

Baclofen influences the threshold at which motoneurons are activated (Capaday, 1995), but it is less likely that these effects contributed to our results because we found no differences in F-waves between patients taking and not taking baclofen. The threshold of motoneurons can also be affected by influences from several descending and spinal pathways including the corticospinal pathway (Matthews, 1959; Feldman and Orlovsky, 1972; Raptis et al., 2010). Due to the lack of specific changes in svMEPs across groups, our results argue for a critical contribution of spinal premotor interneurons that contact the corticospinal tract in the MEP suppression. Spinal circuits, unlike motor cortical circuitry, are constantly in a ready mode to rapidly translate inputs to muscle activity (Cheney and Fetz, 1980; Maier et al., 1998). During voluntary activity, spinal premotor interneurons are able to shape inputs and outputs according to the behavioral context (Prut and Perlmutter, 2003). The significant contribution of spinal premotor interneurons to force generation during precision grip (Takei and Seki, 2013) might result in a decreased need for corticospinal excitation. A possible role of the spinal networks is to gate sensory inputs that are not relevant to the skilled motor behavior (Perez et al., 2005). The consequence of this will be a better control of the selected movement because of less interference from unwanted reflex events produced by sensory inputs. Overall, these results highlight a role of premotoneuronal targets in the control of movement after SCI (Bunday and Perez, 2012b).

\section{References}

Aimonetti JM, Nielsen JB (2002) Cortical excitability and motor task in man: an investigation of the wrist extensor motor area. Exp Brain Res 143:431-439. CrossRef Medline

Alstermark B, Pettersson LG, Nishimura Y, Yoshino-Saito K, Tsuboi F, Takahashi M, Isa T (2011) Motor command for precision grip in the macaque monkey can be mediated by spinal interneurons. J Neurophysiol 106:122-126. CrossRef Medline

Baker SN (2007) Oscillatory interactions between sensorimotor cortex and the periphery. Curr Opin Neurobiol 17:649-655. CrossRef Medline

Barry MD, Bunday KL, Chen R, Perez MA (2013) Selective effects of baclofen on use-dependent modulation of GABAB inhibition after tetraplegia. J Neurosci 33:12898-12907. CrossRef Medline

Bennett KM, Lemon RN (1996) Corticomotoneuronal contribution to the fractionation of muscle activity during precision grip in the monkey. J Neurophysiol 75:1826-1842. Medline

Bunday KL, Perez MA (2012a) Impaired crossed facilitation of the cortico- spinal pathway after cervical spinal cord injury. J Neurophysiol 107:29012911. CrossRef Medline

Bunday KL, Perez MA (2012b) Motor recovery after spinal cord injury enhanced by strengthening corticospinal-motoneuronal synapes. Curr Biol 22:2355-2361. CrossRef Medline

Burke D, Andrews CJ, Knowles L (1971) The action of a GABA derivative in human spasticity. J Neurol Sci 14:199-208. CrossRef Medline

Butler JE, Thomas CK (2003) Effects of sustained stimulation on the excitability of motoneurons innervating paralyzed and control muscles. J Appl Physiol 94:567-575. CrossRef Medline

Butler JE, Larsen TS, Gandevia SC, Petersen NT (2007) The nature of corticospinal paths driving human motoneurones during voluntary contractions. J Physiol 584:651-659. CrossRef Medline

Buys EJ, Lemon RN, Mantel GW, Muir RB (1986) Selective facilitation of different hand muscles by single corticospinal neurones in the conscious monkey. J Physiol 381:529-549. Medline

Capaday C (1995) The effects of baclofen on the stretch reflex parameters of the cat. Exp Brain Res 104:287-296. Medline

Cheney PD, Fetz EE (1980) Functional classes of primate corticomotoneuronal cells and their relation to active force. J Neurophysiol 44:773-791. Medline

Curtis DR, Gynther BD, Lacey G, Beattie DT (1997) Baclofen: reduction of presynaptic calcium influx in the cat spinal cord in vivo. Exp Brain Res 113:520-533. CrossRef Medline

Datta AK, Harrison LM, Stephens JA (1989) Task-dependent changes in the size of response to magnetic brain stimulation in human first dorsal interosseous muscle. J Physiol 418:13-23. Medline

Davey NJ, Romaiguère P, Maskill DW, Ellaway PH (1994) Suppression of voluntary motor activity revealed using transcranial magnetic stimulation of the motor cortex in man. J Physiol 477:223-235. Medline

Davey NJ, Smith HC, Wells E, Maskill DW, Savic G, Ellaway PH, Frankel HL (1998) Responses of thenar muscles to transcranial magnetic stimulation of the motor cortex in patients with incomplete spinal cord injury. J Neurol Neurosurg Psychiatry 65:80-87. CrossRef Medline

Farmer SF, Swash M, Ingram DA, Stephens JA (1993) Changes in motor unit synchronization following central nervous lesions in man. J Physiol 463:83-105. Medline

Feldman AG, Orlovsky GN (1972) The influence of different descending systems on the tonic stretch reflex in the cat. Exp Neurol 37:481-494. CrossRef Medline

Fetz EE, Cheney PD (1987) Functional relations between primate motor cortex cells and muscles: fixed and flexible. Ciba Found Symp 132:98117. Medline

Flament D, Goldsmith P, Buckley CJ, Lemon RN (1993) Task dependence of responses in first dorsal interosseous muscle to magnetic brain stimulation in man. J Physiol 464:361-378. Medline

Galea MP, Darian-Smith I (1997) Manual dexterity and corticospinal connectivity following unilateral section of the cervical spinal cord in the macaque monkey. J Comp Neurol 381:307-319. CrossRef Medline

Hoogewoud F, Hamadjida A, Wyss AF, Mir A, Schwab ME, Belhaj-Saif A, Rouiller EM (2013) Comparison of functional recovery of manual dexterity after unilateral spinal cord lesion or motor cortex lesion in adult macaque monkeys. Front Neurol 4:101. CrossRef Medline

Huesler EJ, Hepp-Reymond MC, Dietz V (1998) Task dependence of muscle synchronization in human hand muscles. Neuroreport 9:2167-2170. CrossRef Medline

Hultborn H, Nielsen JB (1995) H-reflexes and F-responses are not equally sensitive to changes in motoneuronal excitability. Muscle Nerve 18:14711474. CrossRef Medline

Humphrey DR, Reed DJ (1983) Separate cortical systems for control of joint movement and joint stiffness: reciprocal activation and coactivation of antagonist muscles. Adv Neurol 39:347-372. Medline

Isa T, Kinoshita M, Nishimura Y (2013) Role of direct vs. indirect pathways from the motor cortex to spinal motoneurons in the control of hand dexterity. Front Neurol 4:191. CrossRef Medline

Johannsen P, Christensen LO, Sinkjaer T, Nielsen JB (2001) Cerebral functional anatomy of voluntary contractions of ankle muscles in man. J Physiol 535:397-406. CrossRef Medline

Kalsi-Ryan S, Beaton D, Curt A, Duff S, Popovic MR, Rudhe C, Fehlings MG, Verrier MC (2012) The graded redefined assessment of strength sensibility and prehension: reliability and validity. J Neurotrauma 29:905-914. CrossRef Medline 
Kouchtir-Devanne N, Capaday C, Cassim F, Derambure P, Devanne H (2012) Task-dependent changes of motor cortical network excitability during precision grip compared to isolated finger contraction. J Neurophysiol 107:1522-1529. CrossRef Medline

Lang CE, Schieber MH (2003) Differential impairment of individuated finger movements in humans after damage to the motor cortex or the corticospinal tract. J Neurophysiol 90:1160-1170. CrossRef Medline

Lang CE, Schieber MH (2004) Reduced muscle selectivity during individuated finger movements in humans after damage to the motor cortex or corticospinal tract. J Neurophysiol 91:1722-1733. CrossRef Medline

Latash ML, Penn RD, Corcos DM, Gottlieb GL (1989) Short-term effects of intrathecal baclofen in spasticity. Exp Neurol 103:165-172. CrossRef Medline

Lawrence DG, Kuypers HG (1968) The functional organization of the motor system in the monkey. I. The effects of bilateral pyramidal lesions. Brain 91:1-14. CrossRef Medline

Lemon RN (2008) Descending pathways in motor control. Annu Rev Neurosci 31:195-218. CrossRef Medline

Liepert J, Classen J, Cohen LG, Hallett M (1998) Task-dependent changes of intracortical inhibition. Exp Brain Res 118:421-426. CrossRef Medline

Llewellyn M, Yang JF, Prochazka A (1990) Human H-reflexes are smaller in difficult beam walking than in normal treadmill walking. Exp Brain Res 83:22-28. Medline

Maier MA, Bennett KM, Hepp-Reymond MC, Lemon RN (1993) Contribution of the monkey corticomotoneuronal system to the control of force in precision grip. J Neurophysiol 69:772-785. Medline

Maier MA, Perlmutter SI, Fetz EE (1998) Response patterns and force relations of monkey spinal interneurons during active wrist movement. J Neurophysiol 80:2495-2513. Medline

Marino RJ, Barros T, Biering-Sorensen F, Burns SP, Donovan WH, Graves DE, Haak M, Hudson LM, Priebe MM (2003) International standards for neurological classification of spinal cord injury. J Spinal Cord Med 26:S50-S56. Medline

Matthews PB (1959) A study of certain factors influencing the stretch reflex of the decerebrate cat. J Physiol 147:547-564. Medline

Mazevet D, Pierrot-Deseilligny E, Rothwell JC (1996) A propriospinal-like contribution to electromyographic responses evoked in wrist extensor muscles by transcranial stimulation of the motor cortex in man. Exp Brain Res 109:495-499. Medline

Nielsen J, Kagamihara Y (1993) The regulation of presynaptic inhibition during co-contraction of antagonistic muscles in man. J Physiol 464:575593. Medline

Nielsen J, Petersen N (1994) Is presynaptic inhibition distributed to corticospinal fibres in man? J Physiol 477:47-58. Medline

Nishimura Y, Onoe H, Morichika Y, Perfiliev S, Tsukada H, Isa T (2007) Time-dependent central compensatory mechanisms of finger dexterity after spinal cord injury. Science 318:1150-1155. CrossRef Medline

Nishimura Y, Morichika Y, Isa T (2009) A subcortical oscillatory network contributes to recovery of hand dexterity after spinal cord injury. Brain 132:709-721. CrossRef Medline

Osu R, Franklin DW, Kato H, Gomi H, Domen K, Yoshioka T, Kawato M (2002) Short- and long-term changes in joint co-contraction associated with motor learning as revealed from surface EMG. J Neurophysiol 88: 991-1004. Medline

Oudega M, Perez MA (2012) Corticospinal reorganization after spinal cord injury. J Physiol 590:3647-3663. CrossRef Medline

Palleschi G, Conte A, Pastore AL, Salerno G, Giannantoni A, Berardelli A, Carbone A (2014) Modelling recurrent discharge in the spinal $\alpha$-motoneuron: reappraisal of the F wave. Clin Neurophysiol 125:427-429. CrossRef Medline

Perez MA, Field-Fote EC (2003) Impaired posture-dependent modulation of disynaptic reciprocal Ia inhibition in individuals with incomplete spinal cord injury. Neurosci Lett 341:225-228. CrossRef Medline

Perez MA, Lungholt BK, Nielsen JB (2005) Presynaptic control of Ia afferents in relation to acquisition of a novel visuo-motor skill in healthy humans. J Physiol 568:343-354. CrossRef Medline

Perez MA, Lundbye-Jensen J, Nielsen JB (2007) Task-specific depression of the soleus $\mathrm{H}$-reflex after cocontraction training of antagonistic ankle muscles. J Neurophysiol 98:3677-3687. CrossRef Medline

Petersen NC, Butler JE, Taylor JL, Gandevia SC (2010) Probing the corticospinal link between the motor cortex and motoneurones: some neglected aspects of human motor cortical function. Acta Physiol (Oxf) 198:403416. CrossRef Medline

Petersen NT, Butler JE, Marchand-Pauvert V, Fisher R, Ledebt A, Pyndt HS, Hansen NL, Nielsen JB (2001) Suppression of EMG activity by transcranial magnetic stimulation in human subjects during walking. J Physiol 537:651-656. CrossRef Medline

Prut Y, Perlmutter SI (2003) Firing properties of spinal interneurons during voluntary movement. I. State-dependent regularity of firing. J Neurosci 23:9600-9610. Medline

Quevedo J, Eguibar JR, Jiménez I, Rudomin P (1992) Differential action of (-)-baclofen on the primary afferent depolarization produced by segmental and descending inputs. Exp Brain Res 91:29-45. CrossRef Medline

Raptis H, Burtet L, Forget R, Feldman AG (2010) Control of wrist position and muscle relaxation by shifting spatial frames of reference for motoneuronal recruitment: possible involvement of corticospinal pathways. J Physiol 588:1551-1570. CrossRef Medline

Rekand T, Hagen EM, Grønning M (2012) Spasticity following spinal cord injury. Tidsskr Nor Laegeforen 132:970-973. CrossRef Medline

Rothwell JC, Hallett M, Berardelli A, Eisen A, Rossini P, Paulus W (1999) Magnetic stimulation: motor evoked potentials. The International Federation of Clinical Neurophysiology. Electroencephalogr Clin Neurophysiol Suppl 52:97-103. Medline

Rudomin P, Schmidt RF (1999) Presynaptic inhibition in the vertebrate spinal cord revisited. Exp Brain Res 129:1-37. CrossRef Medline

Sakai K, Ugawa Y, Terao Y, Hanajima R, Furubayashi T, Kanazawa I (1997) Preferential activation of different I waves by transcranial magnetic stimulation with a figure-of-eight-shaped coil. Exp Brain Res 113:24-32. CrossRef Medline

Sasaki S, Isa T, Pettersson LG, Alstermark B, Naito K, Yoshimura K, Seki K, Ohki Y (2004) Dexterous finger movements in primate without monosynaptic corticomotoneuronal excitation. J Neurophysiol 92:3142-3147. CrossRef Medline

Takei T, Seki K (2010) Spinal interneurons facilitate coactivation of hand muscles during a precision grip task in monkeys. J Neurosci 30:1704117050. CrossRef Medline

Takei T, Seki K (2013) Spinal premotor interneurons mediate dynamic and static motor commands for precision grip in monkeys. J Neurosci 33: 8850-8860. CrossRef Medline

Taylor JL, Gandevia SC (2004) Noninvasive stimulation of the human corticospinal tract. J Appl Physiol 96:1496-1503. CrossRef Medline

Thomas CK, Häger-Ross CK, Klein CS (2010) Effects of baclofen on motor units paralysed by chronic cervical spinal cord injury. Brain 133:117-125. CrossRef Medline

Trompetto C, Bove M, Marinelli L, Avanzino L, Buccolieri A, Abbruzzese G (2004) Suppression of the transcallosal motor output: a transcranial magnetic stimulation study in healthy subjects. Exp Brain Res 158:133140. Medline

Zaaimi B, Edgley SA, Soteropoulos DS, Baker SN (2012) Changes in descending motor pathway connectivity after corticospinal tract lesion in macaque monkey. Brain 135:2277-2289. CrossRef Medline 